\author{
Kurnia Wijayanti ${ }^{1}$,Andrew Johan ${ }^{2}$, Nana Rochana ${ }^{3}$, Anggorowati ${ }^{4}$, Shofa Chasani ${ }^{5}$ \\ ${ }^{1}$ Mahasiswa Magister Keperawatan Universitas Diponegoro \\ ${ }^{2}$ Dosen Fakultas Kedokteran Universitas Diponegoro. Jl. Prof. H. Soedarto, SH, Tembalang Semarang \\ 50275 \\ ${ }^{3}$ Dosen Departemen IImu Keperawatan Universitas Diponegoro. Jl. Prof. H. Soedarto, SH, Tembalang \\ Semarang 50275 \\ ${ }^{4}$ Dosen Departemen IImu Keperawatan Universitas Diponegoro. Jl. Prof. H. Soedarto, SH, Tembalang \\ Semarang 50275 \\ ${ }^{5}$ Dosen Fakultas Kedokteran Universitas Diponegoro. Jl. Prof. H. Soedarto, SH, Tembalang Semarang \\ 50275
}

\begin{abstract}
ABSTRAK
Musik suara alam merupakan bentuk integrative antara musik klasik dengan suara-suara alam. Pengunaan musik suara alam seperti suara burung, ombak, angin, air mengalir dan lainnya sebagai terapi kesehatan telah mencapai hasil yang memuaskan yaitu meningkatkan relaksasi, memperbaiki kondisi fisik, psikis bagi individu dengan berbagai usia. Penelitian ini bertujuan untuk mengetahui pengaruh pemberian musik suara alam terhadap penurunan kecemasan pasien kritis di ICU. Penelitian ini bermanfaat untuk membantu penyembuhan pasien kritis, sebagai landasan mewujudkan evidence based practice dalam penanganan pasien kritis.

Metode penelitian menggunakan quasi experiment non equivalent dengan pre-post test control group design. Pengambilan sampel consecutive sampling dengan randomized allocation. Responden berjumlah 38 orang yang terdiri dari 20 orang kelompok intervensi dan 18 orang kelompok kontrol. Musik suara alam yang digunakan adalah suara burung dengan kombinasi diberikan 2x30 menit yaitu pada pagi hari (jm08.00-tengah hari), dan malam hari (20.00-22.00) selama 3 hari. Alat ukur kecemasn menggunakan visual analog scale-anxiety (VAS-A). Analisa data menggunakan Wilcoxon dan Mann Whitney.

Hasil dari penelitian ini menunjukkan penurunan kecemasan pada kelompok intervensi dengan nilai untuk pretest $62,25 \pm 7,304$, posttest $41,65 \pm 5,976$, sedangkan pada kelompok kontrol pretest $46,55 \pm 12,76$, posttest $43,00 \pm 12,35$. Hasil uji perbandingan nilai kecemasan sebelum dan sesudah diberikan intervensi pada kelompok intervensi nilai $p=0,000(p<0,05)$ dan kelompok kontrol nilai $p=0,007(p<0,05)$. Sedangkan hasil uji beda kecemasan antara kelompok intervensi dan kelompok kontrol adalah $p=$ $0,000(p<0,05)$ yang berarti ada perbedaan yang bermakna pada tingkat kecemasan antara kelompok intervensi dengan kelompok kontrol.

Kesimpulan. Musik suara alam efektif untuk menurunkan kecemasan pada pasien kritis.
\end{abstract}

Kata Kunci : terapi musik, suara alam, kecemasan.

\title{
NATURE SOUNDS MUSIC TO DECREASED ANXIETY ON CRITICALLY ILL PATIENTS
}

\section{ABSTRACT}

Nature sound music is a combination between classical music with sounds of nature. The use of natural sound music like the sounds of birds, waves, wind, and water flow as a medical therapy has achieved satisfactory results that can improve relaxation, physical condition, and psychological state for individuals of various ages. This study aimed to determine the effect of natural sound music to decreased anxiety on critically ill patients in the ICU. This research is helpful in healing the critical patient, and as the basis for realizing evidence based practice in the management of critically ill patients.

This research is using quasi-experimental non-equivalent to the pre-posttest control group design, with consecutive sampling by randomized allocation. Respondents were 20 people the intervention group and 18 people in the control group. Nature sounds music that was used is the sound of birds with a combination of $2 \times 30$ minutes in the morning (08.00-noon) and in the evening (20:00 to 22:00) for 3 days. Anxiety levels were measured using visual analog scale-anxiety (VAS-A). Data then were analyzed using Wilcoxon and Mann Whitney. 
The results of this study showed a decrease in anxiety in the intervention group with a value of $62.25 \pm 7.304$ pretest, posttest $41.65 \pm 5.976$, whereas the control group pretest $46.55 \pm 12.76,43.00 \pm 12.35$ posttest. The result of the comparison test on the anxiety before and after intervention in the intervention group $p=0.000(p<0.05)$ and in the control group $p=0.007$ ( $p<0.05$ ). While the results of the difference test on the anxiety between the intervention group and the control group were $p=0.000$ ( $p$ $<0.05$ ), which means there is a significant difference in anxiety levels between the intervention group and control group. Conclusion. Music sounds of nature is effective to reduce anxiety in critically ill patients.

Keywords: music therapy, natural sounds, anxiety.

Corresponding Author :

Kurnia Wijayanti, Mahasiswa Magister Keperawatan Universitas Diponegoro

E-mail : Jayahe28@gmail.com

\section{PENDAHULUAN}

Kecemasan merupakan hal yang sering dirasakan pasien menjalani pengobatan atau prosedur di rumah sakit. Sumber kecemasan pada pasien yang dirawat di ruang intensif dapat berupa penyakit yang diderita, perasaan kesepian, rasa takut mengenai ajal, lingkungan seperti pencahayaan yang terus menerus, suara alat yang terdengar sepanjang waktu, serta kesiagaan dari petugas medis. Diperkirakan sekitar $70 \%$ sampai $87 \%$ pasien kritis mengalami kecemasan. Kecemasan dapat mengakibatkan adanya perubahan fisiologis meliputi tekanan darah, heart rate, pernafasan (Biley, Morgan, \& Satherley, 2003), agitasi, peningkatan aktifitas otot/pergerakan, ketakutan (Chlan \& Savik, 2011), ancaman terhadap lingkungan yang asing dengan kebisingan yang terus menerus, teknologi yang canggih, kehilangan privasi, ketidakmampuan untuk berkomunikasi efektif, mobilitas terbatas, gangguan tidur, dan takut mati atau cacat yang umum untuk pengalaman perawatan kritis. Perawat meyakini bahwa pengelolaan kecemasan sangat penting sehingga tidak berubah menjadi ketakutan yang dapat menstimulasi sistem saraf simpatis sehingga mengakibatkan adanya peningkatan kerja pernafasan, permintaan oksigen, dan kerja otot jantung (Chlan \& Savik, 2011). National Center for Complementary/Alternative Medicine (NCCAM) membuat berbagai terapi dan sistem pelayanan dimana mind-body therapy memberikan intervensi dengan teknik untuk memfasilitasi kapasitas berpikir yang mempengaruhi gejala fisik dan fungsi tubuh misalnya perumpamaan (imagery), yoga, terapi seni, berdoa, journaling, biofeedback, humor, tai chi, dan terapi musik (Snyder, M. \& Lindquist, 2002).

Badan penelitian kesehatan dan kualitas perawatan kesehatan di Ronchester, Minnesota merekomendasikan bahwa manajemen kecemasan bisa dilakukan dengan terapi relaksasi seperti musik dan suara alam (nature sound) (Cutshall et al., 2011). Nature sounds music merupakan jenis musik temuan baru akibat modernisasi tehnologi rekaman suara, bentuk integrative musik klasik dengan suara-suara alam. Komposisi suara yang dihasilkan oleh fenomena alam, seperti angin, hujan, laut, sungai, binatang, dan burung. Suara alam juga memiliki tempo yang berbeda, pitch, dan irama yang umumnya lambat atau nada yang tidak tiba-tiba tinggi. Manusia memiliki hubungan yang erat dan kontak dengan alam yang bermanfaat bagi kesehatan (Chiang, 2012). Menurut E.O.Wilson dalam bukunya biophilia mengemukakan bahwa manusia memiliki daya tarik bawaan dengan alam sehingga 
interaksinya dengan alam memiliki efek terapeutik dan penggunaan suara alam tersebut dalam tatanan klinik masih jarang dilakukan (Lechtzin, Bone, Aspirate, Busse, \& Smith, 2010).

\section{METODE}

Penelitian quasi experiment non equivalent dengan pre-post test control group design (Dharma, 2011). Tujuan dari penelitian ini mendiskripsikan perbedaan tingkat kecemasan sebelum dan setelah pemberian intervensi musik suara alam kelompok intervensi dan kontrol, dan mendeskripsikan perbedaan kecemasan antara kelompok intervensi dan kontrol. Pengambilan sampel consecutive sampling dengan randomized allocation. Responden berjumlah 38 orang, 20 orang untuk kelompok intervensi dan 18 orang kelompok kontrol. Musik suara alam yang digunakan adalah suara burung dengan kombinasi diberikan $2 \times 30$ menit yaitu pada pagi hari (jm08.00-tengah hari), dan malam hari (20.00-22.00) selama 3 hari. Kriteria inklusi responden meliputi bersedia menjadi dan mendengarkan musik suara alam, berusia diatas 18 tahun, dirawat di ICU $\geq 48$ jam, GCS 13-15, kecemasan ringansedang, tidak memiliki gangguan pendengaran, menyetujui dan bersedia mendengar musik suara alam.

Analisa univariat menggambarkan karakteristik responden berdasarkan usia jenis kelamis, jenis penyakit dari responden, dan gambaran tingkat kecemasan. Analisa bivariat terlebih dahulu dilakukan uji normalitas mengggunakan uji shapiro wilk dikarenakan jumlah sampel yang sedikit. Pada penelitian ini menggunakan uji nonparametrik wilcoxon karena distribusi data tidak normal. Uji ini untuk mengetahui perbedaan tingkat kecemasan sebelum dan sesudah pada kelompok intervensi dan kelompok kontrol. Sedangkan untuk mengetahui perbedaan tingkat kecemasan antara kelompok intervensi dan kelompok kontrol menggunakan uji Mann Whitney.

\section{HASIL}

Pada bab ini akan menguraikan hasil penelitian tentang pengaruh pemberian intervensi musik suara alam terhadap penurunan kecemasan pasien kritis

Tabel 1. Karakteristik Responden Berdasarkan Jenis Kelamin .

\begin{tabular}{lllll}
\hline \multirow{2}{*}{$\begin{array}{l}\text { Variabel } \\
\text { Jenis Kelamin }\end{array}$} & \multicolumn{2}{l}{ Kelompok Kontrol } & \multicolumn{2}{c}{ Kelompok Intervensi } \\
\cline { 2 - 5 } & $\mathbf{f}$ & $\%$ & $\mathbf{f}$ & $\%$ \\
\hline Laki-Laki & 10 & 56,6 & 7 & 35 \\
\hline Perempuan & 8 & 44,4 & 13 & 65 \\
\hline
\end{tabular}

Tabel 1. menunjukkan bahwa jenis kelamin responden yang dirawat di ruang perawatan kritis pada kelompok intervensi terbanyak perempuan sebesar $65 \%$, dan pada kelompok kontrol laki-laki dan perempuan mempunyai prosentase yang sama yaitu sebesar $50 \%$. 
Gambar 1. Grafik Tingkat Kecemasan Kelompok Intervensi Pasien Kritis

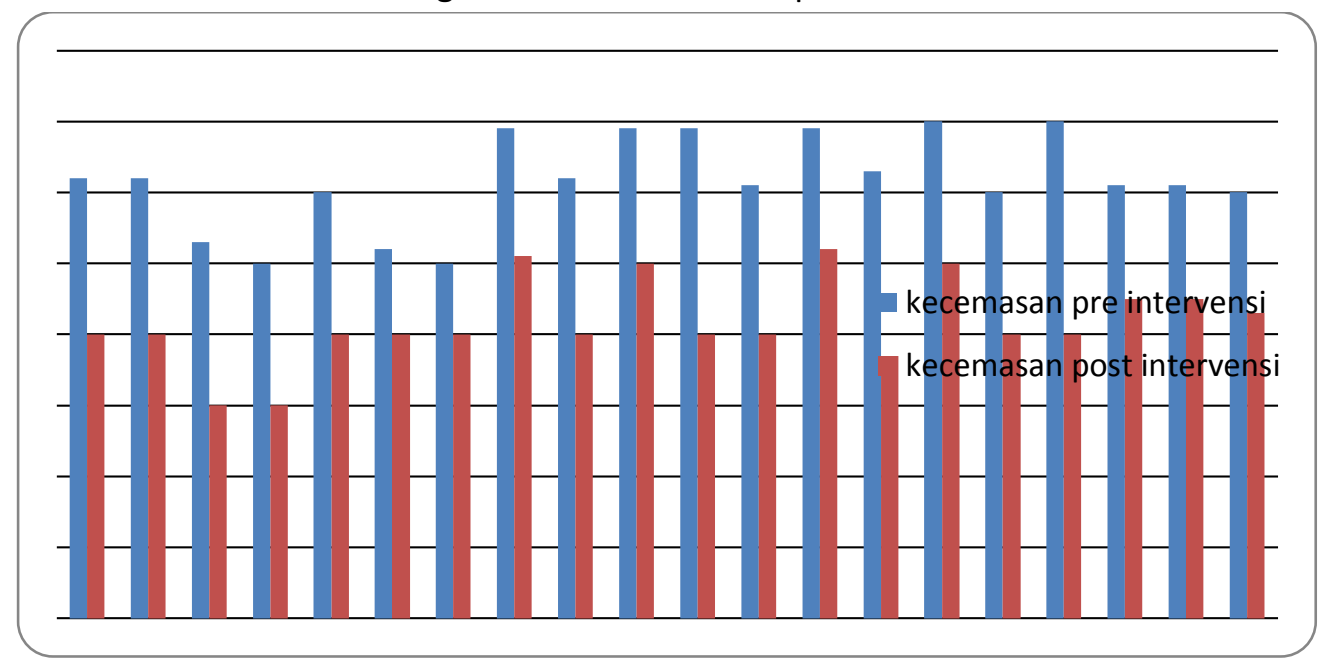

Gambar 1. menunjukkan tingkat kecemasan kelompok intervensi pretest paling tinggi adalah 70 dan paling rendah adalah 50 , sedangkan posttest nilai paling tinggi adalah 52 dan paling rendah adalah 30 .

Gambar 2. Grafik Tingkat Kecemasan Kelompok Kontrol Pasien Kritis

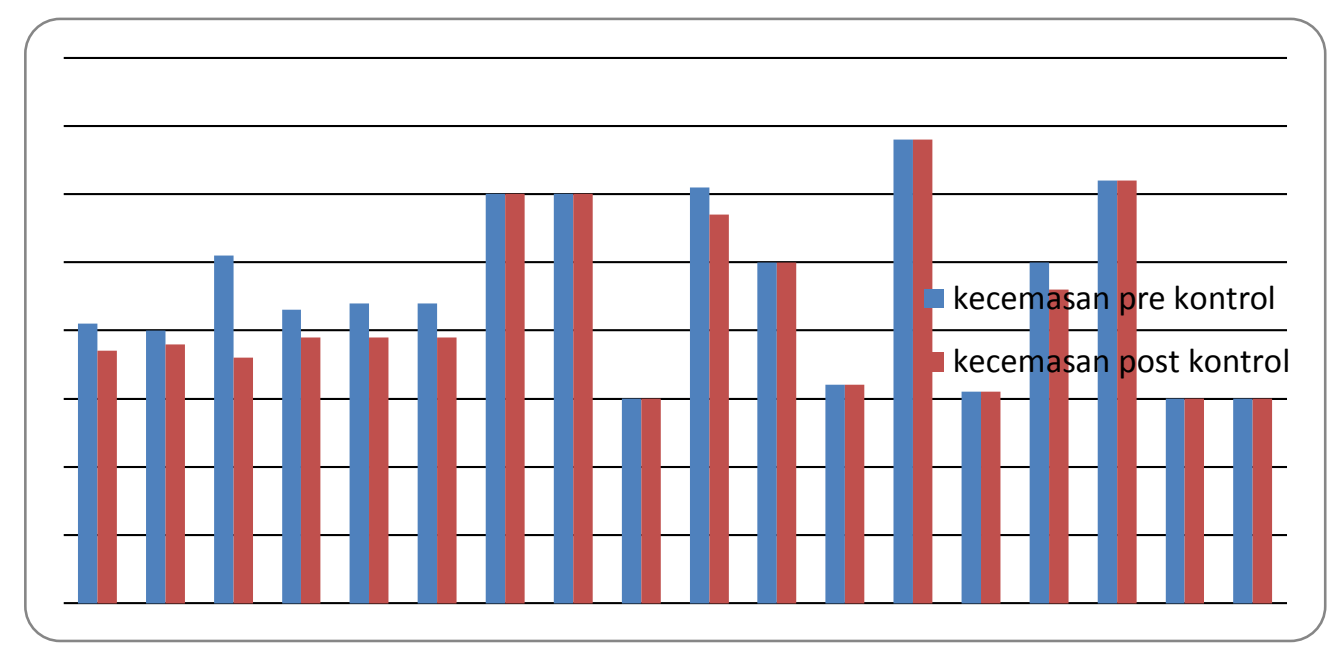

Gambar 2. menunjukkan tingkat kecemasan kelompok kontrol pretest paling tinggi adalah 62 dan paling rendah adalah 30, sedangkan posttest nilai paling tinggi adalah 68 dan paling rendah adalah 30. 
Tabel 2. Perbedaan Kecemasan Sebelum Dan Sesudah Pemberian Terapi Musik Pada Kelompok Intervensi dan Kelompok Kontrol.

\begin{tabular}{ccc}
\hline Kecemasan & Median (Min-Max) & P value \\
\cline { 1 - 1 } Kelompok Intervensi & & Wilcoxon \\
\hline Sebelum & $61,50(50-70)$ & 0,000 \\
\hline Sesudah & $40,00(30-52)$ & \\
\hline Kelompok Kontrol & & \\
\hline Sebelum & $46,06(30-70)$ & \multirow{2}{*}{0,007} \\
\hline Sesudah & $43,56(30-68)$ & \\
\hline
\end{tabular}

Tabel 2. menunjukkan hasil statistik kecemasan kelompok intervensi untuk pretest 61,50(50-70), posttest 40(30-52), sedangkan pada kelompok kontrol untuk pretest $46,06(30-70)$, posttest 43,56(30-68). Hasil uji perbandingan nilai kecemasan sebelum dan sesudah diberikan intervensi pada kelompok intervensi nilai $p=0,000(p<0,05)$ dan kelompok kontrol nilai $p=0,007(p<0,05)$ yang berarti bahwa terdapat perbedaan bermakna kecemasan sebelum dan sesudah pemberian intervensi musik suara alam ( $p$ value $<0,05)$.

Gambar 3. Grafik Perubahan Tingkat Kecemasan Antara Kelompok Intervensi Dan Kelompok Kontrol

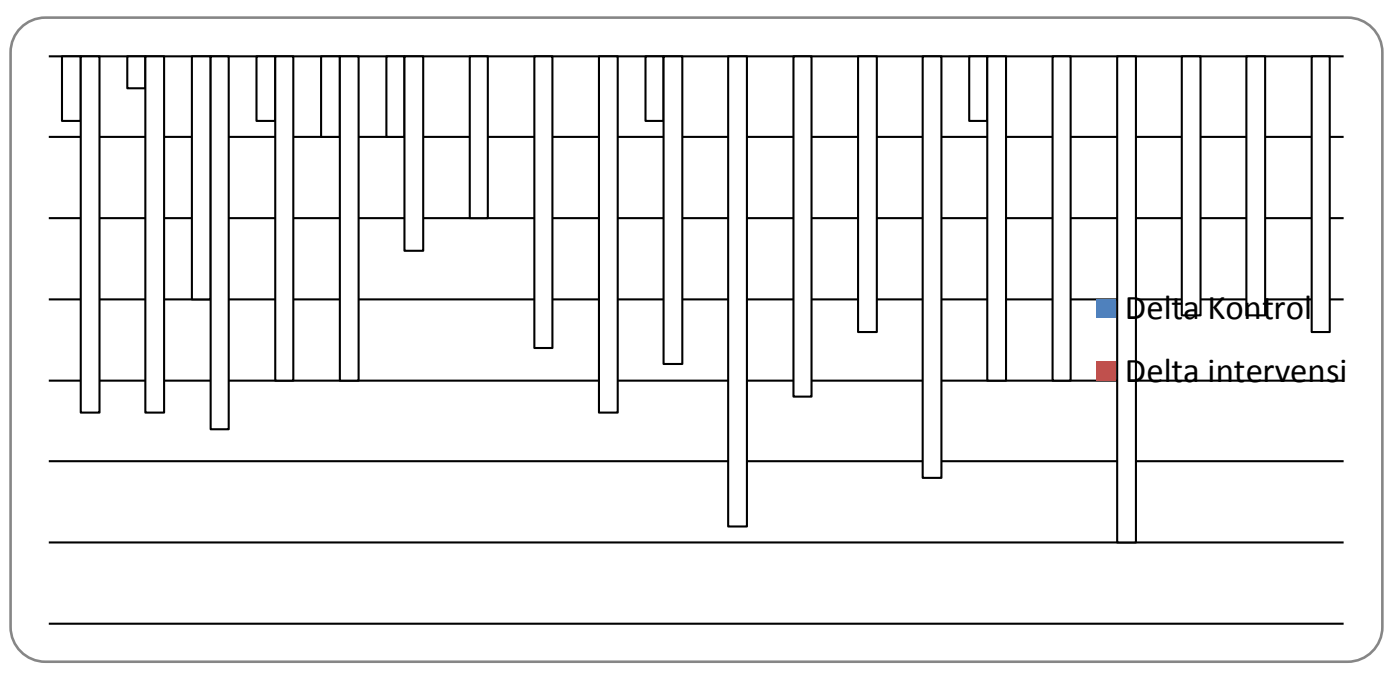

Gambar 3. menunjukkan hasil selisih pretest dan posttest nilai kecemasan pada kelompok intervensi menunjukkan bahwa terdapat penurunan kecemasan paling tinggi sebesar 30 yang ditandai dengan angka 30, sedangkan pada kelompok kontrol terdapat penurunan kecemasan paling tinggi sebesar 15 , yang ditandai dengan angka -15 . 
Tabel 3. Perbandingan Delta Kecemasan Dan Kualitas Tidur Pada Kelompok Intervensi dan Kelompok Kontrol

\begin{tabular}{ccc}
\hline Kecemasan & Mean \pm SD & P value \\
\hline Kelompok Intervensi & $18,83 \pm 5,136$ & \multirow{2}{*}{0,000} \\
\hline Kelompok Kontrol & $2,50 \pm 3,714$ & \\
\hline
\end{tabular}

Tabel 3. menunjukkan hasil perbandingan kecemasan pada kelompok intervensi dan kelompok kontrol yaitu adanya perbedaan yang bernakna antar kedua kelompok dengan nilai $p=0,000(<0,05)$.

\section{PEMBAHASAN}

Hasil data demografi responden usia responden pada kelompok intervensi 49,25(29-65), sedangkan pada kelompok kontrol 49,61(34-70), jenis kelamin didominasi perempuan 13 orang (65\%), laki-laki 7 orang (35\%) pada kelompok intervensi. Dalam penelitian sebelumnya bahwa faktor jenis kelamin, usia, etnik, dan pengalaman pribadi pada musik tertentu akan mempengaruhi penerimaan individu itu sendiri terhadap musik yang didengarnya. Individu itu sendiri yang memberikan pengaruh seberapa efektifnya terapi musik untuk dirinya (Heiderscheit, Breckenridge, Chlan, \& Savik, 2014). Pada penelitian area non kritis yaitu pada pasien post operasi jamtung bahwa didapatkan tidak ada perbedaan yang signifikan pada data demograni, meliputi usia, jenis kelamin,menikah, status pernikahan (Forooghy, Tabrizi, \& Hajizadeh, 2015).

Hasil uji perbandingan nilai kecemasan sebelum dan sesudah diberikan intervensi pada kelompok intervensi nilai $p=0,000(p<0,05)$ dan kelompok kontrol nilai $p=0,007(p<0,05)$ yang berarti bahwa terdapat perbedaan bermakna kecemasan sebelum dan sesudah pemberian intervensi musik suara alam ( $p$ value $<0,05$ ). Penelitian lain yang menggunakan musik pada area non kritis bahwa penggunaan musik suara alam dapat menurunkan kecemasan pada pasein dengan cardiac surgical dengan nilai kecemasan kelompok intervensi $p=0,001$ dan kelompok kontrol $p=0,003$. Penurunan kecemasan terjadi pada kedua kelompok, tetapi perbedaan tidak signifikan secara statistik (Cutshall et al., 2011). Penelitian menyebutkan bahwa musik dapat menurunkan kecemasan pada pasien gagal nafas yang terpasang ventilator daripada pasien yang hanya mendapat perawatan standart di ICU. Dan musik merupakan terapi non farmakologi yang membantu meningkatkan toleransi pasien terhadap penggunaan ventilator (L. L. Chlan \& Weinert, 2013). Penelitian lain bahwa nilai rata-rata penurunan kecemasan pada kelompok intervensi $4.25 \pm 2.60$, sedangkan pada kelompok kontrol7.12 \pm 3.45 (Mahdipour \& Nematollahi, 2012).

Hasil uji beda kecemasan pada penelitian ini antara kelompok intervensi dan kelompok kontrol adalah $p$ value $0,000(p<0,005)$ yang berarti ada perbedaan yang bermakna pada tingkat kecemasan antara kelompok intervensi dan kelompok kontrol. Pada gambar grafik 25 dijelaskan bahwa penurunan kecemasan pada kelompok intervensi paling tinggi yaitu sebesar 30 sedangkan pada kelompok kontrol paling tinggi sebesar 15 yang artinya intervensi musik suara 
alam mempunyai pengaruh terhadap penurunan kecemasan pada pasien kritis. Hal ini sejalan dengan penelitian sebelumnya dimana musik yang diberikan kepada 373 pasien (122 kelompok intervensi dan 125 kelompok kontrol ) di 12 ruang ICU terbukti dapat menurunkan kecemasan pasien yang menggunakan ventilator $\mathrm{p}=0,003$ dan menurunkan penggunaan sedasi. Pada kelompok intervensi menggunakan 3 dosis sedasi sedangkan kelompok kontrol 5 dosis sedasi dari 8 dosis yang ditetapkan (Hoffmann, 2013). Penelitian (Alvarsson, Wiens, \& Nilsson, 2010) dimana pasien diberikan musik suara alam (khususnya suara burung dan suara air mengalir), hasilnya bahwa musik suara alam menciptakan perasaan senang/bahagia, menstimulasi saraf simpatis sehingga mempercepat pemulihan pasien dari stres. Kecemasan yang dirasakan oleh pasien sehingga dapat meningkatkan stimulasi terhadap sistem saraf simpatis, meningkatkan kerja bernafas, meningkatkan kebutuhan oksigen dan stimulai miokardial dengan pemberian musik suara alam dapat memberikan efek sinkronasi yang baik dengan ventilasi mekanik, meningkatkan kenyamanan (Chlan \& Savik, 2011). Dalam database cochrane, menyebutkan bahwa sebanyak 213 pasien dengan ventilasi mekanik yang Penelitian Ismail, (Ismail, 2010) bahwa musik dapat menurunkan kecemasan pada pasien kritis dengan ventilator.diberikan terapi musik menunjukkan adanya penurunan kecemasan. (Bradt, Dileo, \& Grocke, 2010)

Penelitian (Saadatmand et al., 2012) juga menunjukkan penurunan yang progresif terhadap tingkat kecemasan pada 60 responden yang diberikan terapi suara alam. Musik suara alam yang diberikan kepada 120 pasien post coronary artery bypass graft selama penyapihan ventilatormenunjukkan penurunan kecemasan yang signifikan $p=0,002$ (Aghaie, Rejeh, Heravikarimooi, \& Ebadi, 2013).

Penelitian lain tentang pemberian musik suara alam pada area non kritis adalah dimana penggunaan terapi musik pada pasien operasi coronary angioplasty kepada 64 responden, 20-40 menit musik klasik secara signifikan menurunkan kecemsan pada kelompok intervensi dengan nilai $p=0,014$ sedangkan pada kelompok kontrol $p=0,101$ (Forooghy et al., 2015). Jenis musik lain yang digunakan adalah musik harpa yang diberikan selama 20 menit untuk menurunkan kecemasan pada pasien postoperatif vascular thoracic surgical menunjukkan hasil yang signifikan menurunkan kecemasan dengan nilai $p=0,000$ yang diukur 10 menit setelah pemberian musik (Aragon, Farris, \& Byers, 2002). Penggunaan musik untuk menurunkan kecemasan pada pasien yang akan menjalani tindakan coronary angiplasty menunjukkan hasil penurunan kecemasan yang signifikan pada kelompok intervensi ( $32.06 \pm 8.57$ vs $41.16 \pm 10.6$, $\mathrm{p}=0,001)$, dan pada kelompok kontrol hasilnya menunjukkan penurunan yang tidak signifikan (41.91 \pm 9.88 vs. $38.97 \pm 12.77 ; P=0.101$ ) (Forooghy et al., 2015) .

Penggunaan musik klasik, musik pop kontemporer dan musik pop Indonesia dalam menurunkan kecemasan pada pasien dalam kondisi kritis (Ismail, 2010). Review sistematis tentang efek musik untuk mengetahui penurunan kecemasan dan nyeri pada 42 randomized control trial (RCT) dengan 3.936 pasien preoperasi, intraoperasi, dan post operasi menunjukkan hasil yang positif. Evaluasi kecemasan dengan menggunakan state trait anxiety inventory, visual analog scale, numeric rating scale pada 24 studi menunjukkan 12 studi/50\% secara signifikan musik dapat menurunkan skor kecemasan (Nilsson, 2008).

Musik sebagai terapi untuk menurunkan kecemasan sudah dipelajari dan dilakukan sejak lama karena manfaatnya yang besar dalam pengobatan. Musik dapat menstimulasi sistem saraf pusat untuk memproduksi endorfin, dimana endorfin ini dapat menurunkan tekanan darah, 
heart rate dan respiratory rate dan menciptakan suasana yang menyenangkan sehingga dapat meminimalkan rasa takut dan cemas. Selain itu musik dapat memberikan perasaan yang positif dan meningkatkan mood sehingga secara otomatis dapat meningkatkan kemampuan memperbaiki diri secara klinis seperti nyeri dan kecemasan (Forooghy et al., 2015). Sumber kecemasan yang dirasakan oleh responden adalah rasa nyeri, kematian, tidak mengetahui tentang prosedur yang dilaksanakan, ancaman tentang kondisi tubuh, cemas terhadap hasil akhir dari prosedur tertentu, perubahan dalam lingkungan rumah sakit, hilangnya kontrol diri, perubahan konsep diri, hilangnya kemampuan bekerja, hilangnya fungsi peran, kehawatiran akan masa depan, dan pengalaman pertama dirawat di ICU (McKinley S, 2008). Lingkungan ICU yang menakutkan, peralatan ventilator yang menjadi penghambat dalam berkomunikasi, prosedur invasif, suara mesin yang bising dan terus-menerus, kehilangan privasi, gangguan tidur, nyeri, obat-obatan, isolasi dan kontak minimal dengan orang-orang terdekat merupakan hal yang membuat perasaan tidak berdaya memicu terjadinya perasaan cemas pada pasien yang sedang dirawat diruang perawatan kritis (Urden LD, Stacy KM, 2010).

Penelitian ini memiliki heterogenitas responden yang bervariasi, dari tingkat usia, diagnosa medis/jenis penyakitnya, musik yang baru pertama didengar, sehingga menimbulkan efek kecemasan yang berbeda-beda. Pada dasarnya musik suara alam sudah sering didengar dalam kehidupan sehari-hari tetapi tidak dijadikan sebagai terapi sehingga beberapa responden merasa kurang akrab. Dalam pemberian asuhan keperawatan khususnya kecemasan faktor kenyamanan merupakan faktor yang penting untuk dikuasai oleh perawat. Sepanjang abad 19 sampai 20, kenyamanan merupakan dasar pemahaman untuk menjadi perawat yang berkemampuan dan berkarakter dalam memenuhi kebutuhan kenyamanan baik secara fisik maupun mental (Besel, 2006).

Terdapat tiga tipe comfort, yaitu relief, ease dan renewal. Relief didefinisikan sebagai keadaan dimana rasa tidak nyaman berkurang. Ease didefinisikan sebagai hilangnya rasa tidak nyaman yang spesifik; latar belakang teoritikal diperkaya oleh tulisan Henderson tentang kebutuhan dasar manusia. Renewal didefinisikan sebagai keadaan dimana seseorang bangkit dari ketidaknyamanan ketika ketidaknyamanan tersebut tidak dapat dihindari (misalnya anak merasa percaya diri terhadap ambulasi walaupun dia tahu hal tersebut akan memperparah nyeri). Pada akhirnya istilah renewal diubah menjadi transcendence. Transcendence dianggap sebagai hal yang menguatkan dan mengingatkan perawat untuk tidak putus asa dalam membantu pasien dan keluarganya merasa nyaman. Intervensi dalam meningkatan transcendence bertujuan untuk meningkatkan lingkungan, meningkatkan dukungan sosial atau menentramkan hati, seperti terapi relaksasi, musik, pijatan, oral hygiene, pengunjung special, perawatan dengan sentuhan (caring touch), dan memfasilitasi strategi kenyamanan diri sendiri. (Kolcaba, 2003) Dari tipe comfort terdapat tiga kategori dalam intervensi comfort, yaitu (a) intervensi comfort standard untuk mempertahankan homeostasis dan mengontrol nyeri; (b) coaching, melatih untuk mengurangi cemas, menentramkan hati, memberikan informasi, membangkitkan harapan, mendengarkan dan membantu merencanakan penyembuhan; dan (c) comfort food for the soul, memberikan makanan jiwa yang nyaman, termasuk ekstra hal-hal yang 
menyenangkan yang dilakukan oleh perawat agar pasien dan keluarga merasa dirawat dan dikuatkan seperti imaginasi terbimbing (Kolcaba, 2003).

\section{SIMPULAN DAN IMPLIKASI PENELITIAN}

Hasil bahwa terdapat perbedaan yang bermakna antara kelompok kontrol dan kelompok intervensi dengan nilai $p<0,005$. Terapi musik suara alam sebagai salah satu intervensi keperawatan dan standart operasional prosedur dan mengimplementasikan dalam perawatan pasien kritis.

\section{DAFTAR PUSTAKA}

Aghaie, B., Rejeh, N., Heravi-karimooi, M., \& Ebadi, A. (2013). International Journal of Nursing Studies effect of nature-based sound therapy on agitation and anxiety in coronary artery bypass graft patients during the weaning of mechanical ventilation : A randomised clinical trial. International Journal of Nursing Studies. http://doi.org/10.1016/j.ijnurstu.2013.08.003

Alvarsson, J. J., Wiens, S., \& Nilsson, M. E. (2010). Stress recovery during exposure to nature sound and environmental noise, 1036-1046. http://doi.org/10.3390/ijerph7031036

Aragon, D., Farris, C., \& Byers, J. F. (2002). The effects of harp music in vascular and thoracic surgical patients. Alternative Therapy, 8.

Besel, J. M. (2006). The effects of music therapy on comfort in the mechanically patient in the intensif care unit., (April).

Biley, F., Morgan, E., \& Satherley, P. (2003). The effects of music listening on adult patients pre procedural state anxiety in hospital, (1998).

Bradt, J., Dileo, C., \& Grocke, D. (2010). Music interventions for mechanically ventilated patients ( review ), (12). http://doi.org/10.1002/14651858.CD006902.pub3.Copyright

Chiang, et all. (2012). The effects of music and nature sounds on cancer pain and anxiety. Disertasi.

Chlan, L., \& Savik, K. (2011). NIH Public Access : Pattern of anxiety in critically ill patients receiving mechanical ventilatory support, 60(Mv), 1-17. http://doi. org/10.1097/N NR.0b013e 3182160 09c.Patterns

Cutshall, S. M., Olney, T. L., Messner, P. K., Brekke, K. M., lii, T. M. S., Kelly, R. F., \& Bauer, B. A. (2011). Effect of the combination of music and nature sounds on pain and anxiety in cardiac surgical patients: A Randomized Study, 17(4), 16-24.

Dharma, K. K. (2011). Metodologi penelitian keperawatan:panduan melaksanakan dan menerapkan hasil penelitian. Jakarta: Trans Info Media.

Forooghy, M., Tabrizi, E. M., \& Hajizadeh, E. (2015). Effect of Music Therapy on Patients ' Anxiety and Hemodynamic Parameters During Coronary Angioplasty : A Randomized Controlled Trial, 4(2).

Heiderscheit, A., Breckenridge, S. J., Chlan, L. L., \& Savik, K. (2014). Music preferences of mechanically ventilated patients participating in a randomized controlled trial. Music and Medicine, 6(2), 2938.

Hoffmann, L. A. (2013). Music therapy can reduce anxiety in critically ill patients. JAMA. 
Ismail, S. (2010). The effect of music on anxiety reduction in patient with ventilator support.

Kolcaba, K. (2003). Comfort theory and practice: A Vision for holistic health care and research. Canada: Springer Publishing Company.

Lechtzin, N., Bone, U., Aspirate, M., Busse, A. M., \& Smith, M. T. (2010). A Randomized trial of nature scenery and sounds versus urban scenery and sounds to reduce pain in adults. Journal of Alternative Complementary Medicine, 16(9), 965-972. http://doi.org/10.1089/acm.2009.0531

Mahdipour, R., \& Nematollahi, M. (2012). The effect of the music listening and the intensive care unit visit program on the anxiety, stress and depression levels of the heart surgery patients candidates, 5(3), 133-138.

McKinley S, M. C. (2008). Validity of the Faces Anxiety Scale for the assessment of state anxiety in intensive care patients not receiving mechanical ventilation. Journal Psychosom Res, 64(5), 5037.

Nilsson, U. (2008). The anxiety- and pain-reducing effects of music interventions: A Systematic Review. AORN Journal, 87(4). http://doi.org/10.1016/j.aorn.2007.09.013

Saadatmand, V., Rejeh, N., Zayeri, F., Karimooi, M. H., Jasper, M., \& Vaismoradi, M. (2012). effect of nature based sounds intervention on agitation, anxiety, and stress in patients under mechanical ventilator support.

Snyder, M. \& Lindquist, R. (2002). Complementary/alternative therapies in nursing. (4th ed.). New York: Springer.

Urden LD, Stacy KM, L. M. (2010). Critical Care Nursing: Diagnosis and Management. (6th ed.). Kanada: Mosby Elsevier. 